\title{
Global reconstructed daily surge levels from the 20th Century Reanalysis (1871-2010)
}

\author{
Alba Cid ${ }^{\mathrm{a}, *}$, Paula Camus $^{\mathrm{a}}$, Sonia Castanedo ${ }^{\mathrm{b}}$, Fernando J. Méndez $^{\mathrm{b}}$, Raúl \\ Medina $^{\mathrm{a}}$ \\ ${ }^{a}$ Environmental Hydraulics Institute "IH Cantabria", Universidad de Cantabria. Spain \\ ${ }^{b}$ Departamento de Ciencias y Técnicas del agua y del Medio Ambiente, Universidad de \\ Cantabria. Spain
}

\begin{abstract}
Studying the effect of global patterns of wind and pressure gradients on the sea level variation (storm surge) is a key issue in understanding the recent climate change effect on the dynamical state of the ocean.

The analysis of the spatial and temporal variability of storm surges from observations is a difficult task to accomplish since observations are not homogeneous in time, scarce in space, and moreover, their temporal coverage is limited. A recent global surge database developed by AVISO (DAC, Dynamic Atmospheric Correction) fulfilled the lack of data in terms of spatial coverage, but not regarding time extent, since it only includes the last two decades (19922014).

In this work, we use the 20th Century reanalysis V2 (20CR), which spans the years 1871 to 2010 , to statistically reconstruct daily maximum surge levels at a global scale. A multivariate linear regression model is fitted between daily mean ERA-interim sea level pressure fields and daily maximum surge levels from DAC. Following, the statistical model is used to reconstruct daily surges using mean sea level pressure fields from 20CR. The verification of the statistical model shows good agreements between DAC levels and the reconstructed
\end{abstract}

\footnotetext{
*Corresponding author at: Environmental Hydraulics Institute, "IH Cantabria", Universidad de Cantabria, C/Isabel Torres n 15, Parque Científico and Tecnológico de Cantabria, 39011, Santander, Spain. Tel.:+34 942201414

Email address: alba.cid@unican.es (Alba Cid)
}

Preprint submitted to Global and Planetary Change

May 13, 2016

(C) 2016. This manuscript version is made available under the Elsevier user license http://www.elsevier.com/open-access/userlicense/1.0/ 
surge levels from the $20 \mathrm{CR}$. The validation of the reconstructed surge with tide gauges, distributed throughout the domain, shows good accuracy both in terms of high correlations and small errors. A time series comparison is also depicted at specific tide gauges for the beginning of the 20th century, showing a high concordance.

Therefore, this work provides to the scientific community, a daily database of maximum surge levels; which correspond to an extension of the DAC database, from 1871 to 2010. This database can be used to improve the knowledge on historical storm surge conditions, allowing the study of their temporal and spatial variability.

Keywords:

Climate variability, multiple linear regression, statistical modelling, storm surge, historical reconstruction

\section{Introduction}

The storm surge is one of the main variables that describe the dynamical state of the ocean. It is defined as the sea level variation due to wind stress and 4 sea level pressure gradients over the sea surface. The storm surge magnitude has a large spatial variability and can reach extremely high values associated to

6 tropical and extra-tropical storms (extreme storm surge events).

The storm surge is one of the sea level components, and can be extracted 8 from tide gauge records; but since many of the world areas are ungauged, the global coverage is scarce. Besides, areas where instrumental records are available, normally present short time records and hence only recent analysis can be carried out. Nevertheless, there is a global assessment from long centennial 12 records (Marcos et al. 2015) focus on sea level extremes, although it is limited to areas with available tide gauges. One option to overcome these shortcom-

14 ings is the use of numerical models. They enable us to simulate the magnitude of the storm surges at a global scale or in an specific area. In fact, there 16 is a global surge database, the Dynamic Atmospheric Correction from AVISO 
(hereinafter DAC database, http://www.aviso.altimetry.fr/), that provides by means of a statistical model in order to extend the DAC temporal coverage.

40 For achieving this purpose, we define the statistical relationship between the storm surges from DAC database and their drivers (pressure and wind fields 42 from ERA-interim reanalysis, Dee et al. 2011) using multiple linear regression. In this work, although using the term storm surge, we are not reconstructing 44 specific strong events but to a continuous time series of daily values. Once the statistical model is calibrated and verified, we use a global atmospheric database

46 that starts at the end of the 19th century (20th century reanalysis V2, Compo et al. 2011) to reconstruct the storm surge at a global scale and for a long period 
of time (1871-2010).

The work is structured as follows. Section 2 describes the three global databases and the tide gauges used in this study. The methodology of the statistical model is explained in depth in section 3 and its accuracy is shown in

52 section 4 , where the verification results are depicted. Finally, the global reconstruction of the surges and its validation with tide gauges is shown in section 5

${ }_{54}$ Main conclusions are summarised in section 6 .

\section{Databases description}

56

The surge database corresponds to the Dynamic Atmospheric Correction (DAC), produced by CLS Space Oceanography Division using the MOG2D

${ }_{58}$ model from Legos and distributed by Aviso, with support from Cnes (http: //www.aviso.altimetry.fr/). MOG2D (2 Dimensions Gravity Waves model)

${ }_{60}$ is a finite element, barotropic, non-linear, two-dimensional shallow water hydrodynamic model, derived from Lynch and Gray (1979). The model is forced by 62 pressure and wind fields from the European Centre for Medium-range Weather Forecasts (ECMWF) analysis, with a temporal resolution of 6 hours and includ-

64 ing shallow water areas and marginal seas. Barotropic sea level outputs span from September 1992 to present and are provided on a regular grid of $0.25^{\circ} \times 0.25^{\circ}$

${ }_{66}$ every $6 \mathrm{~h}$. The operational DAC database is made of the high frequencies (i.e less than 20 days) obtained from MOG2D barotropic model and the low frequencies of the inverse barometer (IB) assuming a static response of the ocean to the atmospheric forcing, and neglecting wind effects for low frequency (i.e 70 more than 20 days). Therefore, a 20 days high pass (respectively low pass) filtering is applied to separate high and low frequencies (see Eq. 1).

$$
D A C=M O G 2 D(T<20 \text { days })+I B(T>20 \text { days })
$$

Regarding the atmospheric forcing, sea level pressure fields (SLP) were selected from two different global atmospheric databases: ERA-Interim reanalysis 
(Dee et al. 2011) from the ECMWF, which is the DAC forcing field, and the twentieth Century Reanalysis V2 (20CR, Compo et al. 2011).

SLP fields from ERA-Interim, consist of 6 -hourly atmospheric data at $0.75^{\circ}$ of spatial resolution and spanning from 1 January 1979 to present. In this work,

78 only data covering DAC period (1992 - 2014) are selected. These data are used to calibrate and verify the statistical model (see Section 3).

SLP fields from the 20CR are available every 6 hours at a spatial resolution of $2^{\circ}$, covering the period between 1871 and 2010 (i.e. 140 years). These data are used for the statistical reconstruction of surge levels (see Section 5).

Concerning instrumental data, all available tide gauges from the University 84 of Hawaii Sea Level Center (UHSLC, http://uhslc.soest.hawaii.edu/data/ download/rq) were downloaded at hourly scale. From the total amount of

86 643 tide gauges, only those with more than one year of data before 2010 are used to validate the reconstructed surge from $20 \mathrm{CR}$. In order to compare both

88 signals, the tide gauge residuals are obtained by subtracting the astronomical tide (computed using t-tide, Pawlowicz et al. 2002) to the hourly values, and subtracting a 30-day moving average to both, modelled and measured data. This leads to a validation of the storm surge reconstruction at 386 tide gauge locations distributed worldwide.

\section{Statistical modelling methodology}

\subsection{Predictor and predictand definitions}

The aim of the statistical reconstruction is to estimate surge levels (predictand) from local atmospheric conditions (predictor) based on a statistical relationship. Specifically, our interest consists in finding the statistical relationship between mean daily atmospheric conditions and maximum daily surge levels. Following this purpose, the predictand is defined as the maximum of the 4 daily DAC values (DAC has a 6-hourly temporal resolution) at each grid point. The spatial resolution of the statistical reconstruction is determined by 102 the $2^{\circ}$ resolution of the $20 \mathrm{CR}$. This spatial resolution is considered sufficient 
to represent the surge variability at a global scale. Therefore, surge levels are selected from DAC database every $2^{\circ}$.

As mentioned in Section 2, SLP fields from ERA-interim are used to obtain the statistical relationship between these atmospheric fields and surge levels. Although both, surface wind and pressure fields, are the drivers of the storm surge, in this work we are only extracting SLP fields from the atmospheric reanalysis. This is because in global circulation models, sea wind fields are not as well reproduced as sea level pressure fields (Wang et al., 2010); but since the geostrophic wind speed is proportional to the square pressure gradient, SLP gradients are calculated, and taken into account in the statistical modelling, to also have an estimation of the wind speed.

Although SLP from ERA-interim reanalysis has a horizontal resolution of $0.75^{\circ}$, SLP fields and the calculated gradients have been re-arranged in a $2^{\circ}$ grid at a daily scale. The final step in the definition of the predictor is the establishment of the spatial coverage. Taking each of the predictand grid points, a local area of $4^{\circ} \times 4^{\circ}$ enclosing this target point is defined. As a result, the predictor is composed of $9 \mathrm{SLP}$ values and 9 SLP gradients (18 components) centred in the predictand location.

The same process is carried out for the definition of the predictor from $20 \mathrm{CR}$ 122 SLP fields, with the only difference that in this case, data are already in a $2^{\circ}$ grid.

24 Therefore, the predictand consists of daily maximum values of surge levels from September 1992 to December 2014 in a $2^{\circ}$ global grid; the predictor for the statistical model configuration consists of daily means of SLP fields and square SLP gradients from ERA-interim, covering an area of $4^{\circ} \times 4^{\circ}$ centred at the predictand location. Once the statistical model is defined, 20CR daily predictors are used to reconstruct surge levels from 1871 to 2010 at each location (10594 locations). 


\subsection{Description of the statistical model}

132 components (dimensions).

$X\left(x, t_{i}\right)=E O F_{1}(x) \times P C_{1}\left(t_{i}\right)+E O F_{2}(x) \times P C_{2}\left(t_{i}\right)+\ldots+E O F_{N}(x) \times P C_{N}\left(t_{i}\right)$ method used in Camus et al. (2014a) to downscale multivariate wave climate. It comprises a multivariate regression model fitted between daily maximum surge level (predictand) and the principal components $(\mathrm{PCs})$ of the mean daily

The first step in the methodology consists in performing a principal component analysis (PCA) of the predictor to reduce the dimensionality of the problem while preserving the maximum variance of the data sample. PCA projects the original data on a new space, searching for the maximum variance of the sample data. The eigenvectors (empirical orthogonal functions, EOFs) of the data covariance matrix define the vectors of the new space. The transformed components of the original data over the new vectors are the principal components (PCs). The original predictor, which varies with space and time $X(x, t)$, can be expressed as a linear combination of EOFs (accounting for the space variability) and PCs (accounting for the time variability). Eq2 2 shows that at any given time, the predictor can be estimated as the spatial pattern detected (EOF) multiplied by the corresponding coefficient for that instant (PC), adding all the $N$ where $N$ is the number of dimensions in the data, specifically in this case $N=18$.

Prior to PCA, SLP and SLP gradients are standardise to avoid attributes with large values (and larger variances) to dominate the analysis. Then, PCs of the predictor have been calculated for the period 1992 - 2014. Following, we have selected the components that explain the $95 \%$ of the variance. The number of PCs explaining the $95 \%$ of the variance varies spatially between 4 and 12 (not shown) from the total amount of 18 components. Therefore, although in this case the dimension reduction is not highly relevant, PCA is carried out anyway

The statistical method chosen to reconstruct surge levels is based on the 
158

$$
\operatorname{surge}\left(x_{i}, t\right)=a_{i}+b_{1, i} \times P C_{(1)}\left(x_{i}, t\right)+b_{2, i} \times P C_{(2)}\left(x_{i}, t\right)+\ldots+b_{n, i} \times P C_{(n)}\left(x_{i}, t\right)
$$

where $n$ is the number of PCs that achieved a statistical improvement of the

so that this methodology could also be applied to wider predictors (i.e higher dimensions).

The next step consists of establishing the relationship between the predictor PCs that explain the $95 \%$ of the variance and the surge levels (predictand). The multivariate regression model is fitted in a forward procedure: first predictor PC is obtained from the best fit (smallest sum of squared errors, SSE) among each of the components separately $\left(P C_{(1)}\right.$ in Eq 3 . The second predictor PC $\left(P C_{(2)}\right.$ in $\left.\mathrm{Eq}, 3\right)$ is chosen from the rest of the PCs so that it gives the best fit with two predictors, the best predictor selected in the previous model plus one of the remaining potential predictors. The cycle continues until a more complex model does not produce a significant improvement (at the $5 \%$ level of significance) in the multivariate regression fit. This evaluation is based on the F statistics that compare the SSE of fitting a simpler-parameter model with that of a more complex parameter model (Wang et al. 2010). Therefore, although all PCs explaining the $95 \%$ of the variability could be used in the regression model, only those that produce a significant improvement are taken into account.

model: The regression model is fitted for all years except one, which is used to validate the surge reconstruction. Then, the regression model is fitted 22 times (there are 22 complete years of surge levels, 1993-2014). Results of the model verification are shown in Section 4

This methodology allows us to estimate surge levels as a linear combination of the most important PCs. As can be seen from Eq3. surge levels at any given location $\left(x_{i}\right)$ can be estimated from a specific number of PCs, which varies throughout the domain.

results (following $\mathrm{F}$ statistics) and selected in a forward procedure from the 
PCs that explained the $95 \%$ of the variance. $a_{i}, b_{1, i}, \ldots, b_{n, i}$ are the coefficients

obtained in the regression model.

Once the statistical model is defined, SLP and gradients from the 20CR reanalysis are standardised and projected into the EOFs detected for ERAinterim to obtain the PCs for the 20CR predictors. Finally, using the coefficients and the PCs identified as in Eq3, daily surge values can be reconstructed for the $1871-2010$ period.

\section{Model verification}

The verification of the statistical model shows the quality of the fittings in terms of correlation coefficient (Pearson coefficient, $\rho$ ), root mean square error (RMSE), and the RMSE relative to the maximum surge variability at each location ( $\left.R M S E_{\text {relative }}\right)$. Fig 1 shows the spatial distribution of the fitting quality. As can be seen from Fig.1A, correlation coefficients are above 0.65 all along the domain except for the areas located along the north-atlantic coast of South America, the area from the Gulf of Thailand through Indonesia to North Australia, and along the Siberian and Beaufort Seas. An extended area of relative low correlations (around 0.7 ) is located along tropical areas. The explanation for this lies in the fact that the ocean dynamics at high latitudes have smaller space and time scales. The predictor used in the proposed statistical model describes better the dynamical response of the storm surge in those areas in comparison with tropical areas. Besides, the small magnitude of the storm surge in tropical areas is more difficult to reproduce. Fig.1p shows that the RMSE is generally higher in the Northern Hemisphere (maximum values of $\sim 10 \mathrm{~cm}$ ), specifically in semi-enclosed areas as the Hudson bay or the North

Sea, as well as along high latitudes of Russian and Siberian coasts. This is because the storm surge generation at shallow waters, especially in semi-enclosed areas, is highly related to local wind conditions and the local bathymetry. The effect of the bathymetry is taken into account by the statistical model in the predictand term (storm surge), although the non-linear interactions of the storm 
surge with the bathymetry can be partially misrepresented. Therefore, a higher resolution predictor should be required to improve the skill of the statistical model at those areas. Nevertheless, a generalised predictor is used in this study due to the global scale of the storm surge reconstruction. Fig 11; displays the RMSE relative to the maximum surge variability detected at each grid point. This reveals areas of maximum relative errors of around 10\% along equatorial regions, not detected in Fig $1 \mathrm{~b}$ due to the small magnitude of the surge levels along the tropical areas (see Fig 4).

A comparison, between the reconstructed surge and DAC, at a few specific points is also carried out (red dots in Fig,2). Fig 3 shows the time series comparison and the scatter plots at these 6 locations, contrasting DAC data (red lines) with the statistical reconstruction using ERA-interim predictors (blue lines). It can be seen how the equatorial area (point 4) presents the lowest correlations and the highest relative errors, even so, $\rho$ reaches a 0.86 value and the relative error is around 6\%. A general good fitting to the bisector can be seen at all grid points. Fig 3 confirms that the poorest agreement is located at equatorial areas, but although absolute values are not exactly reproduced at grid point 4 , mean levels are well represented. It is also important to notice that the surge magnitude at these tropical zones is about one order of magnitude lower than at the points located in other areas. Time series at the rest of grid points follow DAC data properly.

Last comparison between DAC data and the statistical reconstruction using ERA-interim predictors is represented in Fig.4. It shows the spatial value of the $99.5 \%$ percentile obtained from the complete daily surge series. As can be 38 seen, the spatial pattern is almost identical; main differences are found along the North European coastline, where the statistical reconstruction does not reach the values displayed in the original data. As we mentioned previously, the generation of the storm surge at coastal areas is mainly forced by local winds, for which the resolution of the predictor is not sufficient to resolve local features. Maximum surge values are present in these areas, reaching magnitudes of about $1 \mathrm{~m}$. As already remarked, smallest surges are located around the 

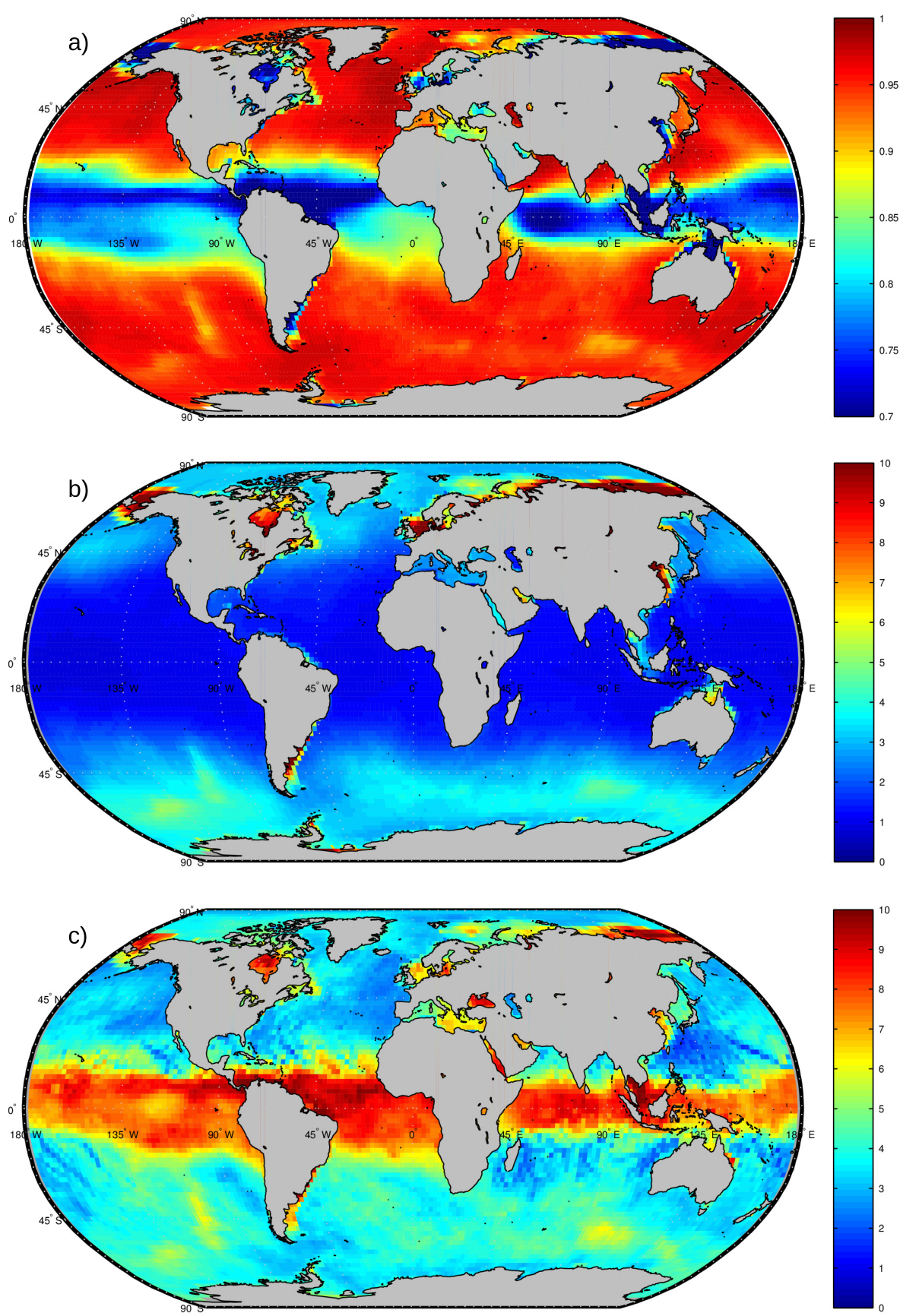

Figure 1: Spatial verification of the statistical reconstruction. a) correlation coefficient $(\rho)$. b) RMSE (cm). c) RMSE relative to the maximum surge variability $(\%)$. 


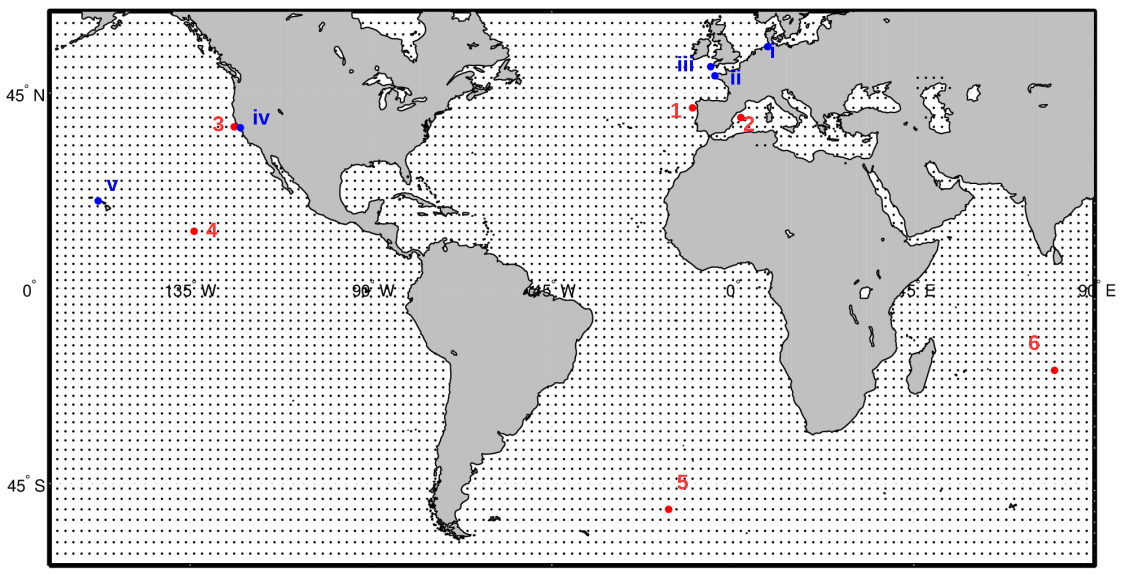

Figure 2: Selected points where a point comparison is carried out. Red grid points are used to validate the statistical model and to compare with the 1871-2010 reconstruction. Blue grid points are compared with tide gauges. Black dots show the spatial resolution of $2^{\circ}$.

equatorial area, where $99.5 \%$ is even negative due to the fact that these areas have high mean pressure conditions (permanent anticyclonic conditions). The extratropical Southern Ocean $\left(40^{\circ} \mathrm{S}-60^{\circ} \mathrm{S}\right)$ is an area with relatively higher values, where the $99.5 \%$ percentile is above $60 \mathrm{~cm}$. Wind conditions at high latitudes of the Southern Hemisphere are the most energetic at a global scale; the general conditions of low pressures present in this area also contribute to maintain high surge levels. 

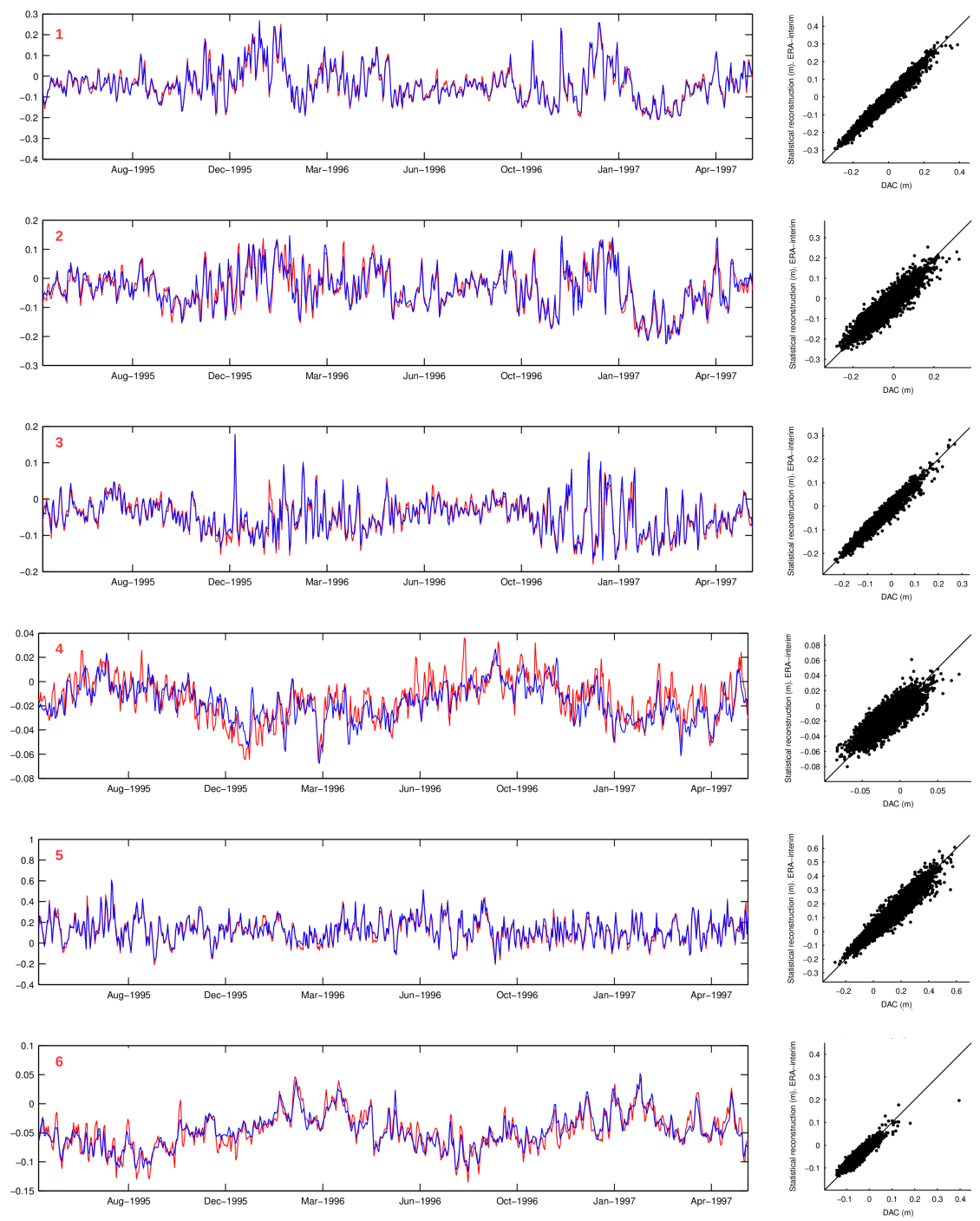

Figure 3: Surge $(\mathrm{m})$ time series comparison and scatter plots at the 6 grid points defined in Fig 2 Red line represents DAC data, blue line corresponds to the statistical reconstruction using ERA-interim predictors. (1): $\rho=0.98 R M S E=1.7 \mathrm{~cm} ;(2): \rho=0.93 R M S E=2.7$ $\mathrm{cm} ;(3): \rho=0.96 R M S E=1.4 \mathrm{~cm} ;(4): \rho=0.86 R M S E=1 \mathrm{~cm} ;(5): \rho=0.95 R M S E=$ $3.6 \mathrm{~cm} ;(6): \rho=0.93 R M S E=1.2 \mathrm{~cm}$ 

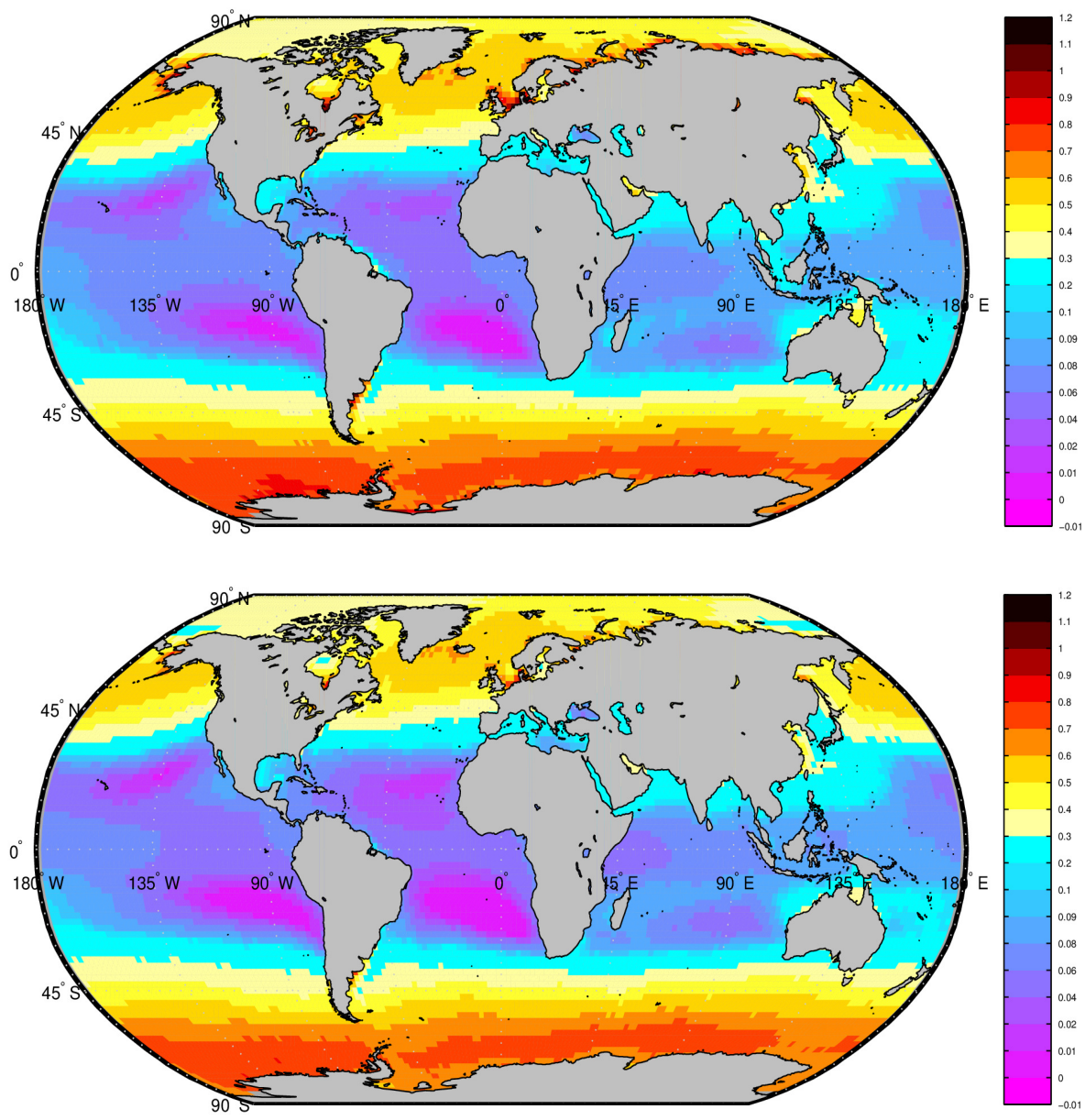

Figure 4: Value (m) of the $99.5 \%$ percentile for DAC data (top) and for surge reconstruction using ERA-interim predictors (bottom). 


\section{Global reconstruction of surges (1871-2010)}

In this section, a global statistical surge reconstruction is performed using

254 2010.

256

\subsection{Comparison during the control period (1992-2010)}

A comparison between DAC data and the reconstructed 20CR surge is car258 Fig 5 shows the spatial comparison, same as in Fig 1 but using 20CR predictors instead of those from ERA-interim. The spatial pattern of both figures is very similar for the 3 statistical indicators. Main differences between Fig 1 and Fig 5 to Antarctica, where the correlation coefficient decreases from 0.95 (Fig.11) to ried out for a control period (1992-2010) where data from both sources coincide. are located in the Southern Hemisphere, specifically in the Pacific Ocean close 0.85 (Fig 5 ) and the relative error is doubled (even so, barely an $8 \%$ ). These differences with the statistical verification can only be due to the quality of the $20 \mathrm{CR}$ reanalysis. The higher quality of the $20 \mathrm{CR}$ upper-air fields over the whole Northern Hemisphere and the mid-latitudes of the Southern Hemisphere has been highlighted when comparing with ERA-40 reanalysis (Compo et al. 2011). Fig 6 shows the time series comparison between DAC data (red lines) and the statistical reconstruction using 20CR predictors (black lines) for the 6 grid points numbered in Fig 2, Grid points 4 (equatorial area) and 6 (Indian Ocean) show extreme storm surge events in the reconstruction that are not present in the original data. This can also be seen from the scatter plots; for 274 those points, an overestimation of the reconstructed surge values regarding DAC data is noticed. The rest of the points show a good agreement, with correlation coefficients and errors of about the same magnitude as in Fig 3 .

Comparing SLP data from 20CR and ERA-interim (not shown) we verified that the aforementioned extreme surges are due to extreme falls in the SLP of $20 \mathrm{CR}$ reanalysis that are not consistent with the SLP in ERA-interim. A brief study has shown us that those drops in the SLP correspond to tropical 
cyclones (TC), included in 20CR but not in ERA-interim. In the 20CR, the

estimated minimum central pressure observations for TCs from the International Best Track Archive for Climate Stewardship (IBTrACS) are assimilated into the reanalysis model. This assimilation may justify the more intense minimum pressures found in $20 \mathrm{CR}$, when comparing to ERA-Interim.

\section{2. $99.5 \%$ percentile of daily surge levels}

The value of the $99.5 \%$ percentile is calculated for the statistical reconstruction using 20CR predictors (see Fig 7). It is done for two periods, one which corresponds to the control period (1992-2010) and that will allow us to compare

the results with the DAC data and the other one which covers the complete 20CR period (1871-2010). As can be seen from Fig, 7, the 99.5\% spatial pattern for the control period (top panel) is very similar to the one corresponding to DAC (top panel in Fig 4). When taking into account the complete period, surge levels decrease generally throughout the domain. The decrease is obvious in the Antarctic surrounding area, where the $99.5 \%$ value decreases from around 80 $\mathrm{cm}$ to $60 \mathrm{~cm}$. A decrease of $10 \mathrm{~cm}$ is found around Canada Arctic coasts. The lower magnitude of the storm surge $99.5 \%$ percentile, for the period 1871-2010, 98 is in agreement with positive trends in the extra-tropical cyclone activity in the Northern Hemisphere and significantly in the Southern Hemisphere (Wang soo al. 2013). However, long-term trends in northeast Atlantic storminess derived from $20 \mathrm{CR}$ and observations are found to be inconsistent in the first half of the twentieth century due to inhomogeneities in 20CR, mostly caused by lower data assimilation (Krueger et al. 2013). Inconsistencies between storm surge record and storm surge reconstruction using 20CR are detected only before 1910 in the North Sea (Dangendorf et al., 2014).

\subsection{Validation with tide gauges}

The surge reconstruction from 20CR predictors has also been compared to measures from tide gauges. The closest grid point to each tide gauge has been 

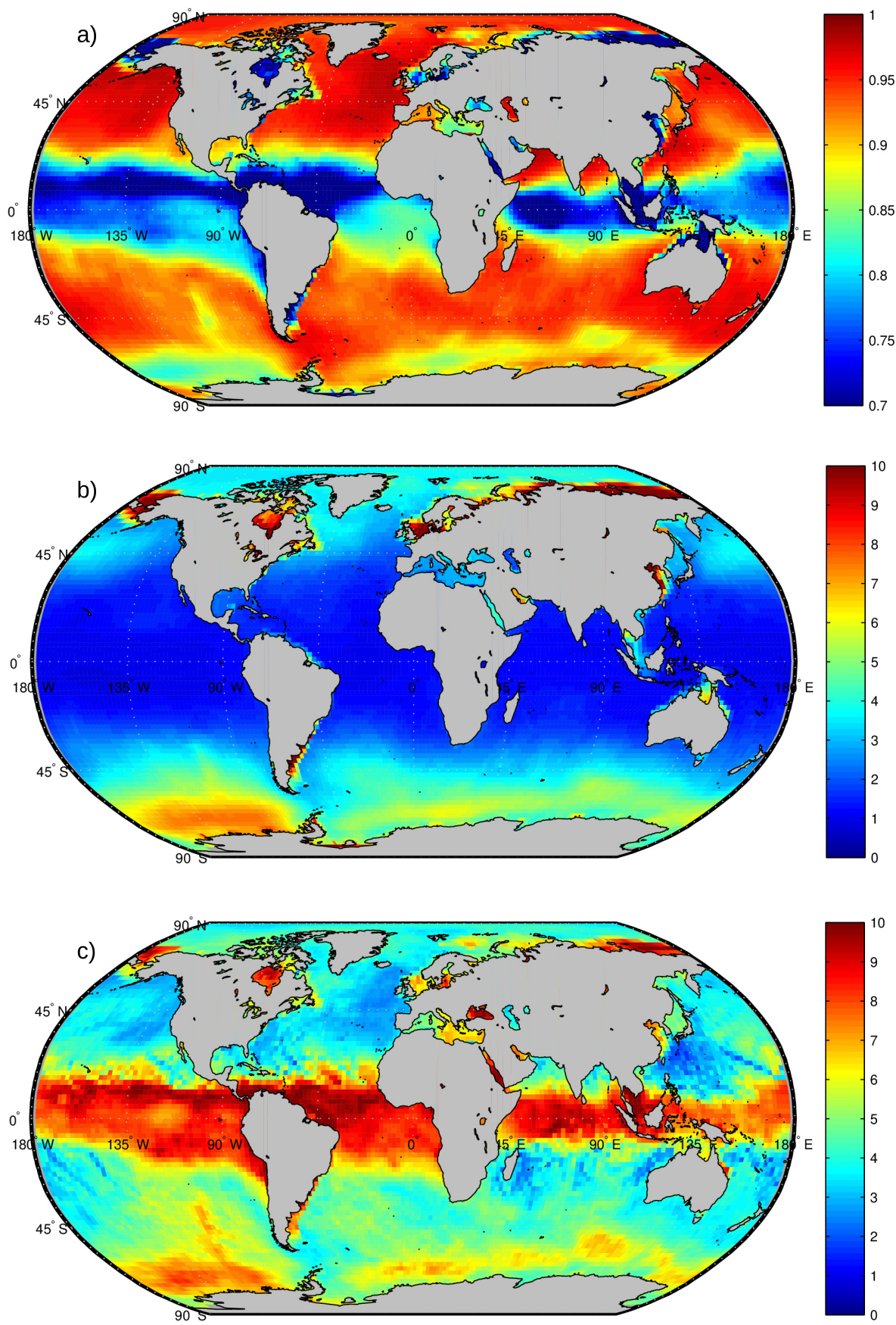

Figure 5: Spatial comparison during the control period between DAC levels and the reconstructed surge using $20 \mathrm{CR}$ predictors. a) correlation coefficient $(\rho)$. b) RMSE (cm). c) RMSE relative to the maximum surge variability $(\%)$. 

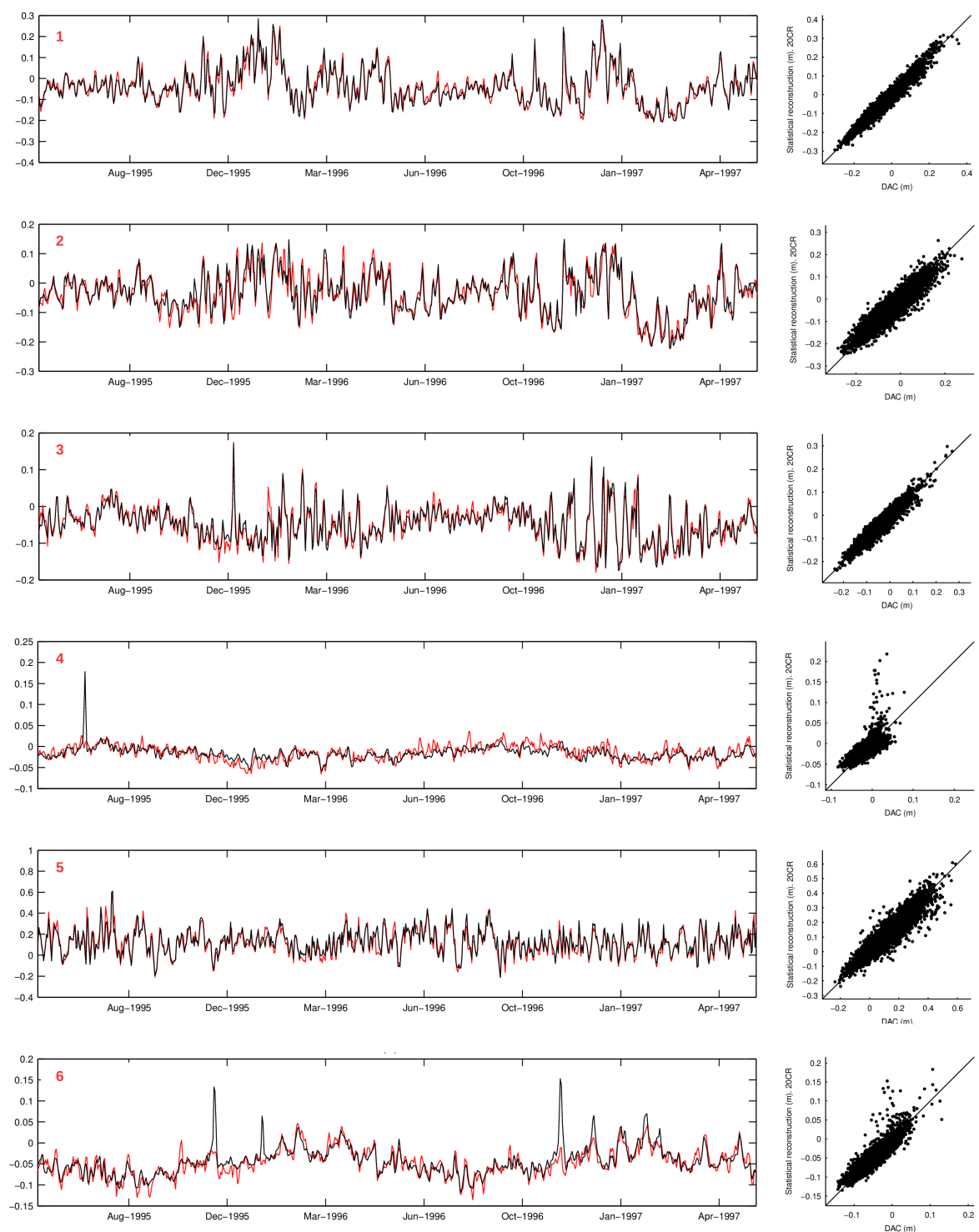

Figure 6: Surge (m) time series comparison at the 6 grid points defined in Fig 2 Red line represents DAC data, black line depicts the surge reconstruction using $20 \mathrm{CR}$ predictors. (1): $\rho=0.97 R M S E=1.8 \mathrm{~cm} ;(2): \rho=0.92 R M S E=2.8 \mathrm{~cm} ;(3): \rho=0.95 R M S E=1.7 \mathrm{~cm} ;$ (4): $\rho=0.71 R M S E=1.4 \mathrm{~cm} ;(5): \rho=0.93 R M S E=4.3 \mathrm{~cm} ;(6): \rho=0.9 R M S E=1.4$ $\mathrm{cm}$ 

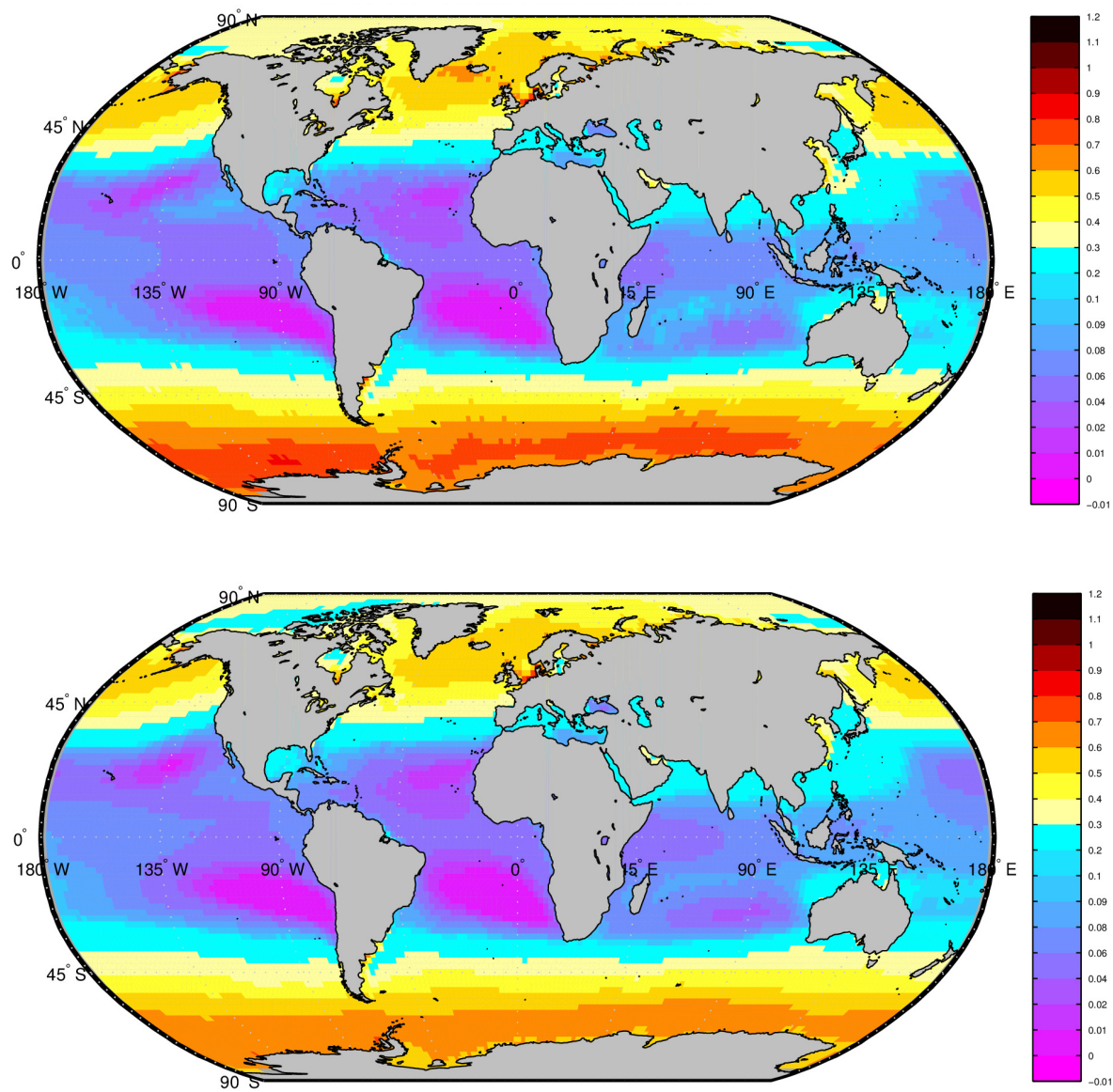

Figure 7: $99.5 \%$ percentile value $(\mathrm{m})$ of the statistical reconstruction using $20 \mathrm{CR}$ for the period 1992-2010 (top) and for the complete 20CR period 1871-2010 (bottom) 
selected from the reconstructed surge database. Fig. 8 presents the validation results for all available tide gauges, where the size of each coloured dot depends on the length of the tide gauge record; small dots, as for example Ammassalik in Greenland, correspond to tide gauges with less than 5 years of measures; medium size dots, as for instance Reykjavik in Iceland, correspond to tide gauges with more than 5 but less than 50 years of records; large dots, as Lerwick in Scotland, are tide gauges with more than 50 years of measures.

The correlation coefficient depicted in Fig. 8a shows that minimum values are above 0.5 except for the tide gauges located in tropical zones. The lowest values are found in Central America, the north of South America and the Gulf of Thailand. Higher correlations are found in extra-tropical areas with values that are generally above 0.7. RMSE (see Fig. 8p) are low at equatorial areas, due to small magnitude of the surge, and up to $15 \mathrm{~cm}$ at the south-east coasts of South America and semi-enclosed areas of the North Sea. Relative errors shown in Fig. 8f reach higher values (up to $20 \%$ ) in islands mainly spread through tropical areas, while at the coasts of the Northern Hemisphere, relative errors are below $5 \%$. This spatial pattern follows the previously found during the verification process, strengthening the fact that the storm surge in tropical zones is more difficult to reproduce. It is worth noting that these differences can also be due to the different dynamics that are gathered in each surge series. The reconstructed signal represents the sea level variation due to meteorologso ical factors only, while the daily measures from tide gauges also account for signals due to oceanographic processes (non-tidal residual). The importance of the oceanographic processes is spatially variable throughout the global ocean (Woodworth and Menéndez, 2015).

A time series comparison is also shown (see Fig 9 for six of the longest UHSLC records (blue dots in Fig,2, i: Cuxhaven, ii: Brest, iii: Newlyn, iv: San Francisco, v: Honolulu, vi: Fort Denison, Sidney), where daily maximum of the tide gauges (red line) are compared to the reconstructed daily maximums from 20CR (black line) for the end of the nineteen century or the beginning of the twenty century. Time series from Brest and Newlyn coincide extremely well, 
both in the timing and the magnitude, with a correlation coefficient of 0.89 , and a RMSE of $6 \mathrm{~cm}$; Cuxhaven, San Francisco and Fort Denison show a slightly lower agreement ( $\rho$ is $0.8,0.75$ and 0.6 , respectively. RMSE is about 25,5 and $7 \mathrm{~cm}$, respectively); Honolulu shows periods where the concordance is low ( $\rho$ is 3440.41 and RMSE is $3 \mathrm{~cm}$ ). Assuming that DAC is of high quality all over the domain, this is the expected result since Brest and Newlyn are located in areas 346 with remarkably high levels of agreement (see Fig 5); Cuxhaven in the North Sea and San Francisco, are placed in areas with slightly smaller correlation 348 coefficients and higher relative errors; Honolulu is located in an area where the lower agreements are found. Besides, DAC performances are also better for coastal tide gauges rather than islands tide gauges (Carrère and Lyard, 2003).

From the comparison with these six tide gauges, it can be seen that the reconstructed storm surge database is able to represent the measured surge signal, also from periods back at the end of the nineteen century with relatively 354 high accuracy. 

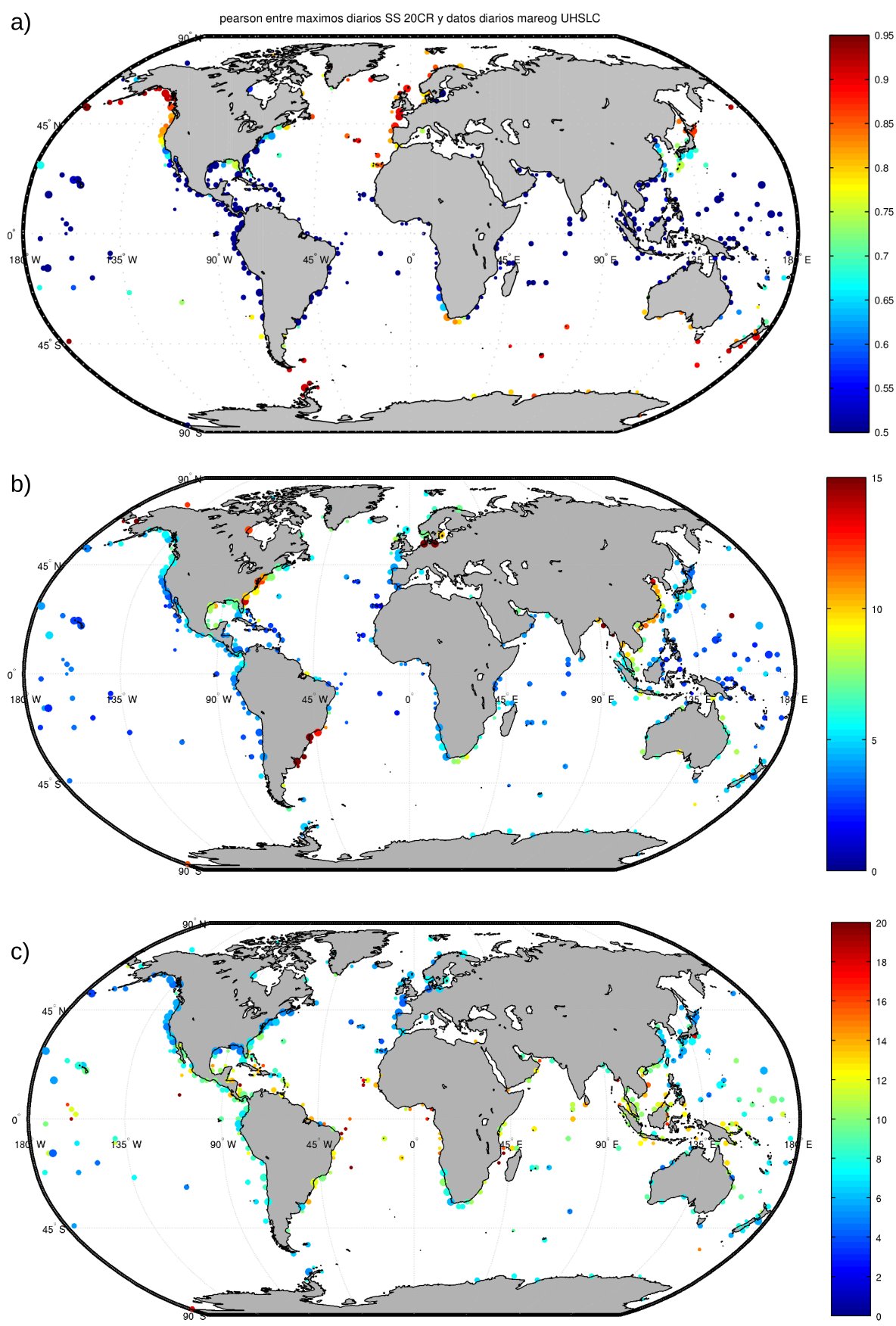

Figure 8: Validation of the reconstructed surge with tide gauges. a) correlation coefficient $(\rho)$. b) RMSE (cm). c) RMSE relative to the maximum surge variability $(\%)$. 

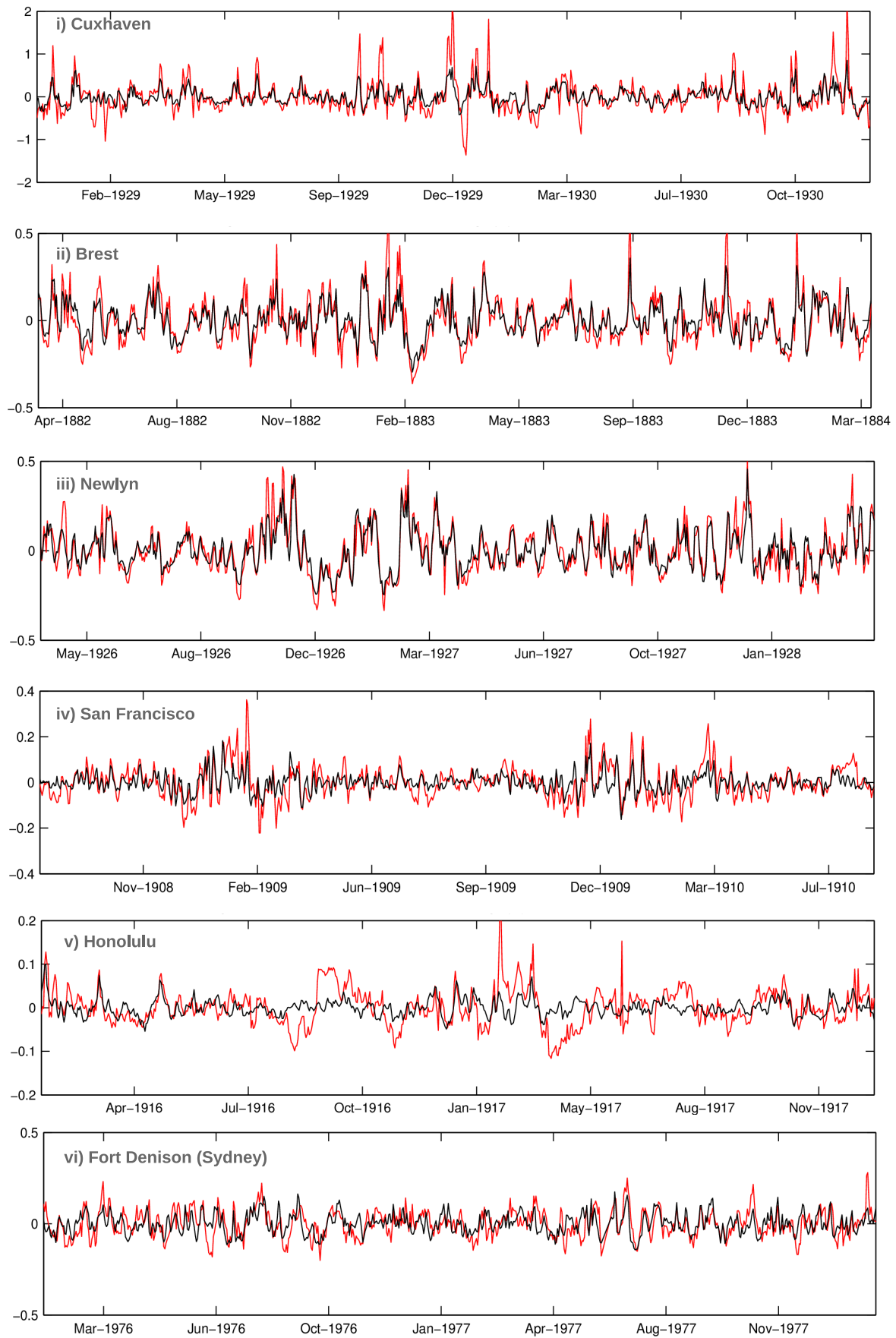

Figure 9: Time series comparison of the reconstructed daily maximum surges (black line) with daily values from tide gauges (red line) at 5 locations (blue dots in Fig 2 . 


\section{Conclusions}

356 models, providing a global storm surge database that estimates daily maximum

This study shows a novel combination of the use of numerical and statistical

surge levels from 1871 to 2010 , at a spatial resolution of $2^{\circ}$. It has been carried out using a statistical model, based on multiple linear regression, that relates the mean SLP and gradients from ERA-interim reanalysis with daily maximum surge levels from DAC database. The model is calibrated and validated, and then used to reconstruct daily maximum surge levels, taking the atmospheric SLP fields from the 20CR as predictors.

The verification of the model showed an extremely high performance all over the world, with minimum agreements (maximum RMSE $E_{\text {relative }}$ of $10 \%$ and minimum $\rho$ of 0.65 ) around equatorial zones and semi-enclosed areas. Two different reasons explain these lower performance areas. In the case of semienclosed areas, a finer predictor resolution would be needed to capture the variability of the atmospheric structures and hence to properly reproduce the surge; in equatorial areas, the small surge magnitude and also the large temporal and spatial scales of the ocean dynamics make more difficult for the statistical model to accurately reproduce the surge.

The comparison between the 20CR reconstructed surge and the original data for the control period, shows a decrease in the agreement at the Southern Hemisphere, specially around the Antarctic area. This is explained in terms of the lower quality of the 20 Century Reanalysis in the Southern Hemisphere (Compo et al., 2011). Around tropical zones, we find extreme data in the reconstruction using $20 \mathrm{CR}$, that correspond to tropical cyclones and that are not present in the DAC database. This is due to the fact that the $20 \mathrm{CR}$ assimilates information about tropical cyclone tracks that are not gathered in the ERAinterim reanalysis, since the detected minimum pressures are more noticeable in 20CR than in ERA-interim.

The validation with a large number of tide gauges has shown the variable spatial quality of the reconstructed surge, and the time series comparison with 
specific tide gauges has also proven the ability of the model to reproduce the surge signal far from the control period. Nevertheless, the extreme values are often underestimated. This because, although not shown, the comparison of the tide gauge residuals with DAC, gives us a very similar picture to the one presented in Fig 8 , meaning that the selected predictand database does not reproduce maximum values accurately.

It is important to note, that at high latitudes there is a variable ice coverage that would eliminate the surge signal, but since DAC database provides sea level data throughout all the domain, the statistical model presented here also finds the relationship between the atmospheric forcing and the oceanic response at those areas.

96 All in all, we have proved here the good ability of the statistical model to reproduce daily maximum surges. The global obtained database provides daily surge values for 140 years, and can be freely used by the scientific community to study, for instance, the long term-variability (decadal variations) during the 20th Century, similarly to what it is done by Marcos et al. 2015 for tide gauge extremes. An interesting application would also be the use of these data as hydrodynamic boundary conditions for numerical downscaling studies. An added value of this method is not only the database but also the tailor-made predictors for each specific location worldwide; meaning that this study provides daily sea level pressure-induced predictors that can be used as covariates in non-stationary or time-dependent models (Méndez et al. 2007; Menéndez and Woodworth 2010, Serafin and Ruggiero 2014), or that can also be used to set the statistical model using surge results from regional models that would estimate maximum values with more accuracy.

Future work regarding the improvement of the predictor's resolution will be carried out at specific areas to show how this affects the predicted surge. This methodology could also be applied to regional climate projections of surge levels for different climate change scenarios.

\section{Acknowledgements}


This work has been partially funded by the Spanish Ministry of Economy

Carrère, L., Lyard, F., 2003. Modeling the barotropic response of the global and Competitiveness under the research project PLVMA (TRA2011- 28900). The authors would like to thank the University of Hawaii Sea Level Center for the tide gauge data. The DAC data (Dynamic Atmospheric Correction) are produced by CLS Space Oceanography Division and distributed by Aviso, with support from Cnes (http://www.aviso.altimetry.fr/). 20th Century Reanalysis V2 are data provided by the NOAA/OAR/ESRL PSD from their Web site at http://www.esrl.noaa.gov/psd/.

\section{References}

Calafat, F.M., Gomis, D., 2009. Reconstruction of Mediterranean sea level fields for the period 1945-2000. Global and Planetary Change 66, 225-234. doi:10.1016/j.gloplacha.2008.12.015

Camus, P., Méndez, F.J., Losada, I.J., Menéndez, M., Espejo, A., Pérez, J., Rueda, A., Guanche, Y., 2014a. A method for finding the optimal predictor indices for local wave climate conditions. Ocean Dynamics 64, 1025-1038. doi:10.1007/s10236-014-0737-2.

Camus, P., Menéndez, M., Méndez, F.J., Izaguirre, C., Espejo, A., Cánovas, V., Pérez, J., Rueda, A., Losada, I.J., Medina, R., 2014b. A weather-type statistical downscaling framework for ocean wave climate. Journal of Geophysical Research: Oceans 119, 7389-7405. doi:10.1002/2014JC010141. ocean to atmospheric wind and pressure forcing - comparisons with observations. Geophysical Research Letters 30, 1275. doi:10.1029/2002GL016473.

«s8 Casas-Prat, M., Wang, X.L., Sierra, J.P., 2014. A physical-based statistical method for modeling ocean wave heights. Ocean Modelling 73, 59-75. URL: http://www.sciencedirect.com/science/article/pii/ S1463500313001893, doi $10.1016 /$ j.ocemod.2013.10.008. 
Compo, G.P., Whitaker, J.S., Sardeshmukh, P.D., Matsui, N., Allan, R.J., Yin, X., Gleason, B.E., Vose, R.S., Rutledge, G., Bessemoulin, P., BroNnimann, S., Brunet, M., Crouthamel, R.I., Grant, a.N., Groisman, P.Y., Jones, P.D., Kruk, M.C., Kruger, a.C., Marshall, G.J., Maugeri, M., Mok, H.Y., Nordli, O., Ross, T.F., Trigo, R.M., Wang, X.L., Woodruff, S.D., Worley, S.J., 2011. The Twentieth Century Reanalysis Project. Quarterly Journal of the Royal Meteorological Society 137, 1-28. doi:10.1002/qj.776.

Dangendorf, S., Müller-Navarra, S., Jensen, J., Schenk, F., Wahl, T., Weisse, R., 2014. North sea storminess from a novel storm surge record since AD 1843. Journal of Climate 27, 3582-3595. doi 10.1175/JCLI-D-13-00427.1.

Dee, D.P., Uppala, S.M., Simmons, a.J., Berrisford, P., Poli, P., Kobayashi, S., Andrae, U., Balmaseda, M.a., Balsamo, G., Bauer, P., Bechtold, P., Beljaars, a.C.M., van de Berg, L., Bidlot, J., Bormann, N., Delsol, C., Dragani, R., Fuentes, M., Geer, a.J., Haimberger, L., Healy, S.B., Hersbach, H., Hólm, E.V., Isaksen, L., Kållberg, P., Köhler, M., Matricardi, M., Mcnally, a.P., Monge-Sanz, B.M., Morcrette, J.J., Park, B.K., Peubey, C., de Rosnay, P., Tavolato, C., Thépaut, J.N., Vitart, F., 2011. The ERA-Interim reanalysis: Configuration and performance of the data assimilation system. Quarterly 460 J Journal of the Royal Meteorological Society 137, 553-597. doi 10.1002/qj. 828

Espejo, A., Camus, P., Losada, I.J., Méndez, F.J., 2014. Spectral Ocean Wave Climate Variability Based on Atmospheric Circulation Patterns. Journal of 464 Physical Oceanography 44, 2139-2152. URL: http://journals.ametsoc. org/doi/abs/10.1175/JPO-D-13-0276.1, doi:10.1175/JPO-D-13-0276.1.

Giorgi, F., Christensen, J., Hulme, M., von Storch, H., Whetton, P., Jones, R., Mearns, L., Fu, C., Arritt, R., Bates, B., Benestad, R., Boer, G., Buishand, A., Castro, M., Chen, D., Cramer, W., Crane, R., Crossly, J., Dehn, M., Dethloff, K., Dippner, J., Emori, S., Francisco, R., Fyfe, J., Gerstengarbe, F., Gutowski, W., Gyalistras, D., Hanssen-Bauer, I., Hantel, M., Hassell, D., 
Heimann, D., Jack, C., Jacobeit, J., Kato, H., Katz, R., Kauker, F., Knutson,

Menéndez, M., Woodworth, P.L., 2010. Changes in extreme high water levels Gregor, J., Miller, N., Murphy, J., Ribalaygua, J., Rinke, A., Rummukainen, M., Semazzi, F., Walsh, K., Werner, P., Widmann, M., Wilby, R., Wild, M., Xue, Y., 2001. Regional Climate Information- Evaluation and Projections. URL: http://epic.awi.de/4973/

Krueger, O., Schenk, F., Feser, F., Weisse, R., 2013. Inconsistencies between long-term trends in storminess derived from the $20 \mathrm{CR}$ reanalyn sis and observations. Journal of Climate 26, 868-874. URL: http: //journals.ametsoc.org/doi/abs/10.1175/JCLI-D-12-00309.1, doi 10. 1175/JCLI-D-12-00309.1.

Lynch, D.R., Gray, W.G., 1979. A wave equation model for finite element tidal computations. Computers \& Fluids 7, 207228. URL: http://www.sciencedirect.com/science/article/pii/ 0045793079900379, doi $10.1016 / 0045-7930$ (79) 90037-9

Marcos, M., Calafat, F.M., Berihuete, Á., Dangendorf, S., 2015. Long-term variations in global sea level extremes. Journal of Geophysical Research: Oceans , n/a-n/aURL: http://doi.wiley.com/10.1002/2015JC011173, doi 10. 1002/2015JC011173.

Méndez, F.J., Menéndez, M., Luceño, A., Losada, I.J., 2007. Analyzing monthly extreme sea levels with a time-dependent GEV model. Journal of Atmospheric and Oceanic Technology 24, 894-911. doi:10.1175/JTECH2009.1.

based on a quasi-global tide-gauge data set. Journal of Geophysical Research: Oceans 115, 1-15. doi:10.1029/2009JC005997.

Müller-Navarra, S.H., Giese, H., 1999. Improvements of an empirical model to forecast wind surge in the German Bight. Deutsche Hydrographische Zeitschrift 51, 385-405. URL: http://link.springer.com/10.1007/ BF02764162, doi $10.1007 / \mathrm{BF} 02764162$ 
Wang, X.L., Feng, Y., Compo, G.P., Swail, V.R., Zwiers, F.W., Allan, R.J.,

Pawlowicz, R., Beardsley, B., Lentz, S., 2002. Classical tidal harmonic analysis including error estimates in MATLAB using TDE. Computers and Geosciences 28, 929-937. doi:10.1016/S0098-3004(02)00013-4.

Serafin, K.A., Ruggiero, P., 2014. Simulating extreme total water levels using a time-dependent, extreme value approach. Journal of Geophysical Research: Oceans 119, 6305-6329. URL: http://doi.wiley.com/10.1002/ 2014JC010093, doi:10.1002/2014JC010093.

Sardeshmukh, P.D., 2013. Trends and low frequency variability of extratropical cyclone activity in the ensemble of twentieth century reanalysis. Climate Dynamics 40, 2775-2800. URL: http://link.springer.com/10.1007/ s00382-012-1450-9, doi $10.1007 / \mathrm{s} 00382-012-1450-9$.

12 Wang, X.L., Feng, Y., Swail, V.R., 2012. North Atlantic wave height trends as reconstructed from the 20th century reanalysis. Geophysical Research Letters 39, n/a-n/a. URL: http://doi.wiley.com/10.1029/2012GL053381, doi:10.1029/2012GL053381.

Wang, X.L., Swail, V.R., Cox, A., 2010. Dynamical versus statistical downscaling methods for ocean wave heights. International Journal of Clima18 a tology, n/a-n/aURL: http://doi.wiley.com/10.1002/joc.1899, doi 10. 1002/joc.1899.

520 Woodworth, P.L., Menéndez, M., 2015. Changes in the mesoscale variability and in extreme sea levels over two decades as observed by satellite altimetry. 522 \. Journal of Geophysical Research: Oceans 120, 64-77. URL: http://doi. wiley.com/10.1002/2014JC010363, doi:10.1002/2014JC010363. 